Article

\title{
Low-Cost Radiometer for Landsat Land Surface Temperature Validation
}

\author{
Jonathan Miller *, Aaron Gerace ${ }^{\mathbb{D}}$, Rehman Eon, Matthew Montanaro and Robert Kremens \\ and Jarrett Wehle \\ Rochester Institute of Technology, 54 Lomb Memorial Drive, Rochester, NY 14624, USA; \\ gerace@cis.rit.edu (A.G.); rse4949@rit.edu (R.E.); montanaro@cis.rit.edu (M.M.); kremens@cis.rit.edu (R.K.); \\ jtw9947@rit.edu (J.W.) \\ * Correspondence: jmm1004@rit.edu; Tel.: +1-330-277-9679
}

Received: 2 December 2019; Accepted: 22 January 2020; Published: 28 January 2020

\begin{abstract}
Land Surface Temperature (ST) represents the radiative temperature of the Earth's surface and is used as input to hydrological, agricultural, and meteorological science applications. Due to the synoptic nature of satellite imaging systems, ST products derived from space-borne platforms are invaluable for estimating ST at the local, regional, and global scale. In the past two decades, an emphasis has been placed on the need to develop algorithms necessary to deliver accurate surface temperature products to support the needs of science users. However, corresponding efforts to validate these products are hindered by the availability of quality ground-based reference measurements. The NOAA Surface Radiation Budget (SURFRAD) network is commonly used to support ST validation efforts, but their instrumentation is broadband $(4-50 \mu \mathrm{m})$ and several of their sites lack spatial uniformity. To address the apparent deficiencies within existing validation networks, this work discusses a prototype radiometer that was developed to provide surface temperature estimates to support validation efforts for spaceborne thermal instruments. Specifically, a prototype radiometer was designed, built, and calibrated to acquire ground reference data to be used to validate ST product(s) derived from Landsat 8 image data. Lab-based efforts indicate that these prototype instruments are accurate to within $1.28 \mathrm{~K}$ and initial field measurements demonstrate agreement to Landsat-derived ST products to within $1.37 \mathrm{~K}$.
\end{abstract}

Keywords: Landsat; TIRS; land surface temperature; SURFRAD; radiometer; thermal infrared; calibration and validation

\section{Introduction}

Measurement of surface temperature (ST) is critical for a variety of Earth science applications, e.g., monitoring potential climate change [1-3], detecting areas of drought [4-6], predicting areas of vector-borne diseases [7], and measuring evapotranspiration [8-10]. Several algorithms necessary to deliver accurate ST products have been developed for existing imaging systems (e.g., MODIS, AVHRR, ABI, VIIRS and most recently, TIRS [11-14]). As technology advances and sensor systems are designed with increased sensitivity, there is a fundamental need among the scientific community to drive down errors in satellite-derived surface temperature measurements. Some ST users desire that spaceborne temperature products be retrieved to within an accuracy of $1 \mathrm{~K}$ or better [15]. With an increased demand of ST product accuracy comes the apparent need for validation of these products. In the early 2000s, a comprehensive validation of MODIS ST products was conducted using a worldwide ground-based instrumentation network. The measurements acquired during this campaign were compared to MODIS-derived ST measurements to characterize the fidelity of the product [16]. The expense involved in such a campaign is not easily repeatable, pointing to the increased need for a simpler validation tool. 
In January 2018, the Committee on Earth Observation Satellites (CEOS) Working Group on Calibration and Validation (Land Product Validation Subgroup) identified six existing ground-based networks that could potentially be used to assess the fidelity of ST products [17]. The outcome documented by this working group of thermal experts led to three findings. Firstly, the identified networks are too sparse (in a spatial sense) to validate a global product. Secondly, the instrumentation used are not ideal for ST validation as these sites were not developed specifically for this application. Thirdly, expanding the number and quality of ground-based reference data is imperative to ensuring high-quality, well-characterized surface temperature products [17].

Nevertheless, several efforts in recent years have taken advantage of the National Oceanic and Atmospheric Administration (NOAA) Surface Radiation budget (SURFRAD) network for ST product validation [11-14]. SURFRAD is a network of seven sites in different climate regions of the United States that were surveyed for spectral uniformity over a $10 \mathrm{~km}$ radius [18]. The surface temperature at each site is calculated from data measured by two Epply pyrgeometers. One pyrgeometer faces toward the Earth and a second points up toward the sky where they record the surface upwelled and sky downwelled thermal irradiance, respectively. The pyrgeometers consist of a temperature-controlled thermopile sensor that records over a broad range of the electromagnetic spectrum (4 $\mu \mathrm{m}$ to $50 \mu \mathrm{m})$. The sampling rate is once per second but the data is smoothed over a three-minute window to dampen high-frequency fluctuations in the measured signal [18]. A silicon dome is attached to the outside of the pyrgeometer to protect the thermopile from wind, which may significantly impact measured temperature [18].

Due to the broadband spectral nature of the pyrgeometer, two potential issues may arise. Firstly, solar reflected radiance in the mid-wave infrared may affect the surface temperature estimation. Secondly, the emissivity is not completely defined from 4 to $50 \mu \mathrm{m}$ for most materials, so the impact of emissivity uncertainty on the final recorded temperature is not apparent. Biases and residual errors reported in recent validation efforts may be attributed to these instrument limitations in conjunction with the spatial non-uniformity of several SURFRAD sites as observed by the spaceborne sensor. An inconsistent ST bias ranging from $0.5 \mathrm{~K}$ to $2 \mathrm{~K}$ and a consistent standard deviation of over $2 \mathrm{~K}$ are widely reported in the literature [11-14]. Given the current ground-based instrumentation, validation efforts will not be able to decouple residual error due to uncertainty in the spaceborne instrument, the algorithm used to derive ST, and the ground-based system used for validation. As such, the need for more advanced ground-based equipment is apparent to properly assess ST product fidelity. The work conducted here by the Rochester Institute of Technology (RIT) focused on the design and implementation of a small, low-cost, field-deployable prototype radiometer. The prototype radiometer was designed to serve as a validation tool for surface temperature products derived from Landsat 8 Thermal Infrared Sensor (TIRS) image data and, as such, contains two spectral channels that mirror the Landsat 8 thermal bands. By windowing the wavelengths of interest, incident solar radiation is filtered and measurements can be acquired over a spectral range where emissivity is well-defined. This paper discusses the radiometer's lab-based characterization, field-implementation, and validation efforts against Landsat's ST product.

\section{Methodology}

The radiance recorded by a sensor viewing the Earth contains contributions from both the target and the atmosphere. Mathematically the sensor-reaching radiance $\left(L_{s}\right)$ can be expressed as

$$
L_{s}=\left[\varepsilon L_{B B}+(1-\varepsilon) L_{d}\right] \tau+L_{u} \quad\left[\frac{\mathrm{W}}{\mathrm{m}^{2} \mathrm{sr} \mu \mathrm{m}}\right]
$$

where $\varepsilon$ is the emissivity of the target, $L_{B B}$ is the blackbody radiance, $L_{d}$ is the downwelled atmospheric radiance, $L_{u}$ is the upwelled atmospheric radiance, and $\tau$ is the atmospheric transmission (note that all variables are band-effective values). When a sensor is in close proximity to the target ( $3 \mathrm{~m}$ in this study), the upwelled atmospheric radiance $\left(L_{u}\right)$ is zero and the atmospheric transmission $(\tau)$ is equal to one. 
Additionally, the sensor must be calibrated in order to relate the raw detector output to at-aperture spectral radiance.

\subsection{Design and Instrumentation}

Similar to the pyrgeometers used in the SURFRAD network, the prototype radiometers developed here take advantage of thermopile technology. A thermopile is an electric device that records voltage as a function of the temperature difference between two thermocouples [19]. One thermocouple remains at a known temperature while the other is sensitive to, and changes temperature with, incoming thermal radiation [19]. For the prototype described here, ST-60 thermopiles were obtained from Dexter Research Center with spectral band-limiting filters to resemble the Landsat TIRS sensor bands shown in Figure 1. One band (Channel A) is centered at $10.6 \mu \mathrm{m}$ and the other (Channel B) is centered at $12.3 \mu \mathrm{m}$, both having a 52-degree field-of-view. Thermopiles were chosen primarily due to their flexibility, i.e., they are customizable to the spectral windows of interest so that band-specific emissivities can be utilized in the measurement process. The specifications of both the SURFRAD pyrgeometer and the prototype radiometer can be seen in Table 1 . The major difference between the two instruments is the spectral range to which the instruments are sensitive; the prototype radiometer is windowed to be more like Landsat.

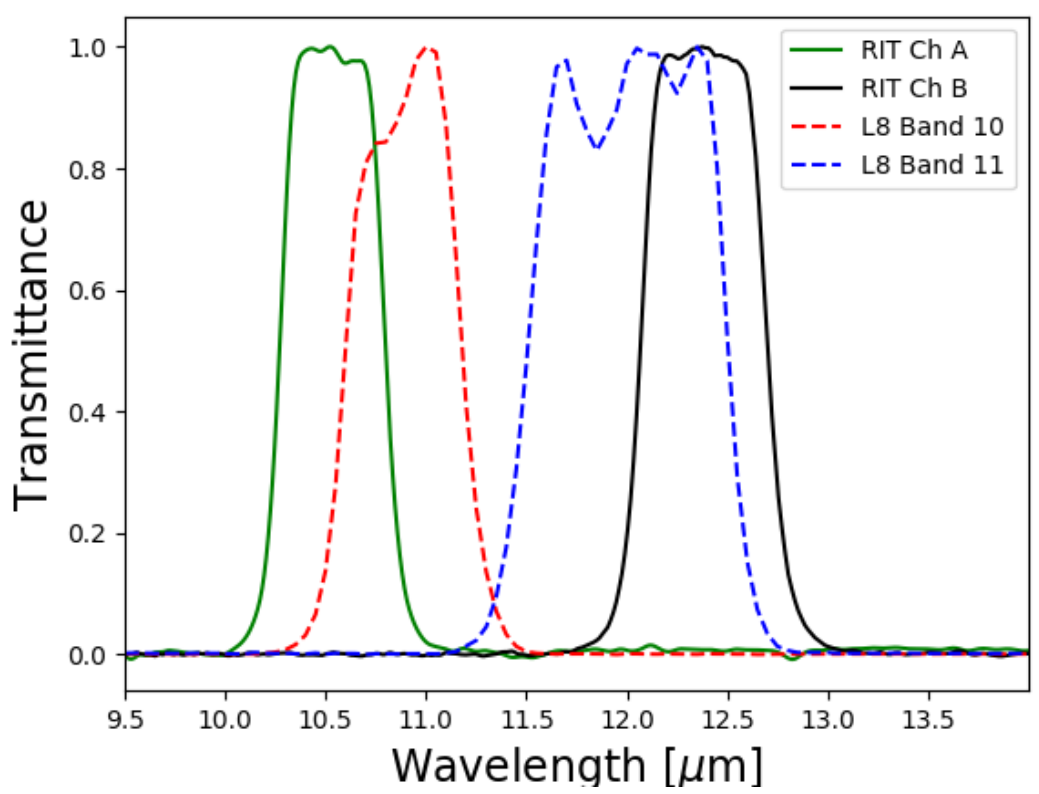

Figure 1. Radiometer spectral response for Channel A and B centered at $10.6 \mu \mathrm{m}$ and $12.33 \mu \mathrm{m}$ respectively, and for Landsat 8 band 10 and 11 centered at $10.9 \mu \mathrm{m}$ and $12.0 \mu \mathrm{m}$, respectively.

Table 1. Comparison of the SURFRAD pyrgeometers and the prototype radiometers specifications.

\begin{tabular}{ccc}
\hline Specifications & SURFRAD & Prototype Radiometer \\
\hline Spectral Range & 4 to $50 \mu \mathrm{m}$ & $10.6 \mu \mathrm{m}(\mathrm{Ch} . \mathrm{A}), 12.3 \mu \mathrm{m}(\mathrm{Ch} . \mathrm{B})$ \\
Field of View & $180 \mathrm{deg}$ & $52 \mathrm{deg}$ \\
Temperature Range & 243 to $323 \mathrm{~K}$ & 250 to $348 \mathrm{~K}$ \\
\hline
\end{tabular}

An environmental sensor was incorporated into the radiometer package to collect temperature, humidity, and atmospheric pressure data. These data are useful for atmospheric characterization and for redundancy. An off-the-shelf Bosch BME 280 sensor was selected as the environmental sensor due to its low cost and ease of integration. The accuracy of the BME sensor is $\pm 0.5 \mathrm{~K}$ for temperature and $\pm 3 \%$ for relative humidity. The completed instrument, protected by a waterproof case, can be seen in Figure 2. 


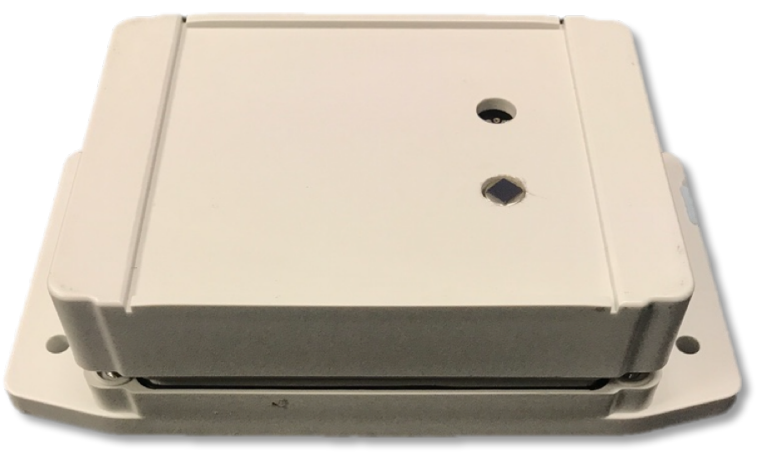

Figure 2. Prototype radiometer with a Dexter ST-60 two-band thermopile. These prototype radiometers are approximately $16 \mathrm{~cm} \times 9 \mathrm{~cm} \times 4 \mathrm{~cm}$ in size, and weigh roughly $0.2 \mathrm{~kg}$.

\subsection{Lab Based Characterization}

The radiometer records voltage for each channel along with the temperature of the detector $\left(T_{d}\right)$ and outputs from the BME sensor. For the prototype radiometer to validate the Landsat 8-derived ST product, the output channel voltage must first be related to target temperature. The output voltage to temperature relation is completed in the lab environment by using a known temperature and emissivity source. A Santa Barbara Infrared (SBIR) Infinity differential blackbody was used in the lab effort to characterize the prototype sensor. The blackbody head has an 8.05-inch square aperture surface, a spectral emissivity of greater than $0.995(8-14 \mu \mathrm{m})$, and is controllable over a temperature range of $248-348 \mathrm{~K}$ with an accuracy of $0.01 \mathrm{~K}$ [20]. Once the radiometer voltage-to-temperature relationship is determined, it is used for all further measurements to convert output signal into the target temperature. Additionally, the instrument performance was characterized in the lab to determine sensitivity to environmental conditions and noise. Further characterization was then performed in real-world conditions in the field.

\subsubsection{Instrument Calibration}

Each prototype radiometer must be characterized and calibrated before it can be implemented in the field. An empirical relationship, derived by Dexter Research, is used to relate output voltage measurements to the target temperature, as shown in Equation (2) [21].

$$
V_{\text {out }}=F\left(\varepsilon T_{s}^{n}+F_{1} T_{o p t}^{n}-T_{d}^{n}\right) \quad[V]
$$

where:

- $\quad V_{\text {out }}=$ output voltage from the radiometer (Ch. A or Ch. B)

- $\quad \varepsilon=0.995$ (SBIR blackbody)

- $\quad T_{S}=$ Temperature of the source (SBIR blackbody)

- $T_{o p t}=$ Temperature of the optics (Assumed to be equal to $T_{d}$ )

- $\quad T_{d}=$ Temperature of the detector measured by a thermocouple (same as optics)

- $\quad \mathrm{n}, \mathrm{F}, \mathrm{F} 1$ = constants ( $\mathrm{n}$ is the power law, and F/F1 are dependent on geometry)

Calibration coefficients for Equation (2) (n, F, and $\mathrm{F}_{1}$ ) were developed by conducting temperature sweeps of the blackbody from $273 \mathrm{~K}$ to $318 \mathrm{~K}$ at $1 \mathrm{~K}$ increments in which radiometer data was acquired at each increment. Since $T_{d}$ is measured by an internal thermocouple, and the emissivity and temperature of the lab blackbody are known, the three coefficients are solved by using a least-squares regression. Once the coefficients are derived, they remain fixed and the temperature of an object can be determined using Equation (3), as long as the object's band-effective emissivity is known.

$$
T_{s}=\left[\frac{1}{\varepsilon}\left(\frac{V_{\text {out }}}{F}-F_{1} T_{\text {opt }}^{n}+T_{d}^{n}\right)\right]^{\frac{1}{n}} \quad[K]
$$


A dwell test was performed to estimate the prototype radiometer's change in radiance corresponding to one unit of change in temperature, known as Noise-Equivalent Change in Temperature (NE $\Delta \mathrm{T})$, at three blackbody temperatures $(283,293,303 \mathrm{~K})$. A final measurement at $283 \mathrm{~K}$ was repeated at the end of the test to characterize potential drift in the system. Referring to Figure 3, measurements were obtained for each temperature for approximately one hour and the NE $\Delta \mathrm{T}$ was calculated as the standard deviation of the collected data at each temperature. Table 2 shows the average difference between the predicted versus actual blackbody temperatures (in column 2) and the corresponding NE $\Delta \mathrm{T}$ values (in column 3) for the prototype radiometer. Table 2 illustrates that, in this lab test, the prototype radiometers are able to measure the blackbody temperature to within $1.28 \mathrm{~K}$ of the actual temperature and exhibit an NE $\Delta \mathrm{T}$ of approximately $0.20 \mathrm{~K}$ across a range of temperatures $(283,293,303 \mathrm{~K})$. Figure 3 also shows that the system is stable, based on the repeatability of predicting the $283 \mathrm{~K}$ temperature at the end of the test.

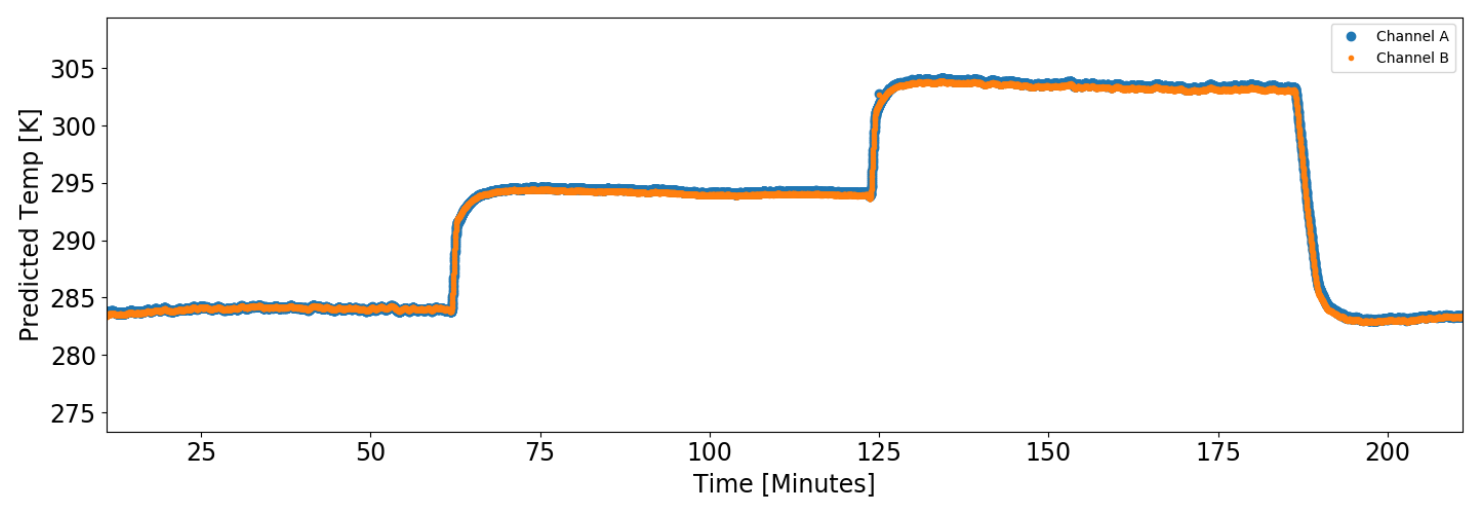

Figure 3. Measured temperatures from the prototype radiometer for the dwell test observing the lab blackbody, which was performed to characterize the NE $\Delta \mathrm{T}$ of the radiometers.

Table 2. Measured temperatures from the radiometer for the dwell test performed to characterize the $\mathrm{NE} \Delta \mathrm{T}$ and drift of the prototype radiometer.

\begin{tabular}{ccc}
\hline Blackbody Temperature & Predicted Difference from Actual Temperature & NE $\Delta \mathrm{T}$ \\
\hline $283 \mathrm{~K}$ & Ch A: $1.03 \mathrm{~K}$ & Ch A: $0.14 \mathrm{~K}$ \\
& Ch B: $1.01 \mathrm{~K}$ & Ch B: $0.16 \mathrm{~K}$ \\
$293 \mathrm{~K}$ & Ch A: $1.28 \mathrm{~K}$ & Ch A: $0.14 \mathrm{~K}$ \\
& Ch B: $1.08 \mathrm{~K}$ & Ch B: $0.14 \mathrm{~K}$ \\
$303 \mathrm{~K}$ & Ch A: $0.55 \mathrm{~K}$ & Ch A: $0.20 \mathrm{~K}$ \\
& Ch B: $0.34 \mathrm{~K}$ & Ch B: $0.20 \mathrm{~K}$ \\
$283 \mathrm{~K}$ & Ch A: $1.06 \mathrm{~K}$ & Ch A: $0.12 \mathrm{~K}$ \\
& Ch B: $1.04 \mathrm{~K}$ & Ch B: $0.14 \mathrm{~K}$ \\
\hline
\end{tabular}

\subsubsection{Environmental Effects}

Initial field experiments were conducted with the lab characterized prototype units in the Spring of 2019. As seen in Figure 4a, a large variation in measured temperature was recorded while viewing a grass field target. This phenomenon was not observed in the lab, indicating that environmental parameters were potentially impacting the measured temperatures. To understand and potentially mitigate these effects, a series of lab tests were conducted where the radiometer was subjected to wind, heat, and vibration while staring at a $303 \mathrm{~K}$ blackbody. 
a)

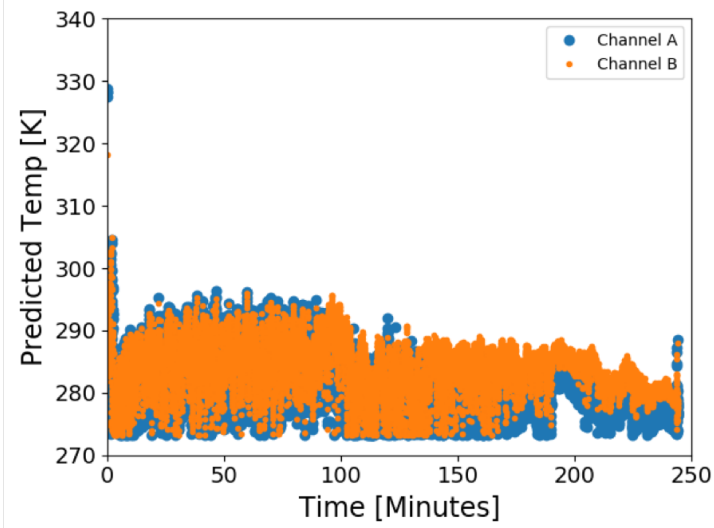

b)

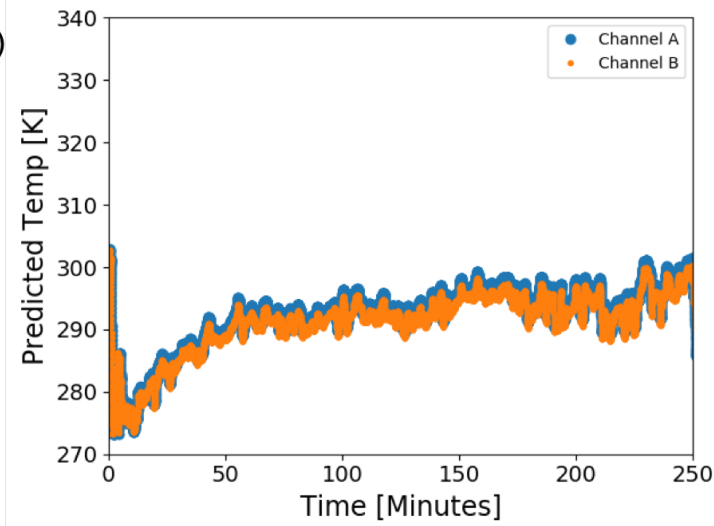

Figure 4. (a) Field collected data during a Landsat pass without wind protection or insulation for solar loading. (b) Field collected data with wind protection and insulation integrated into the prototype radiometer design.

Wind was introduced to the setup by using a fan to blow air directly over the front of the sensor. The fan was turned on and off intermittently to simulate a variable breeze and left on to simulate a constant breeze. Both cases introduced significant variations in the estimated temperatures. The noise in Figure 4a also indicated that solar loading was a potential contributor to temperature measurement uncertainty. To simulate solar loading in the lab setting, an external heat source was introduced in close proximity to the front of the radiometer. The addition of heat to the front of the sensor changed the response initially but quickly settled out. The final test on the radiometer was a vibration test. While staring at the blackbody, the radiometer was introduced to a series of vibrations of varying intensity and duration. No correlation was established between the vibration and variation in temperature calculation.

The SURFRAD pyrgeometers design includes two features to combat the wind and solar effect. Firstly, the pyrgeometer has active heating or cooling to keep the thermopile at a near-constant temperature, eliminating the solar loading effect [18]. Instead of using active heating and cooling to reduce the solar loading effect, the prototype radiometer was wrapped in insulation to help stabilize its internal temperature. Active heating and cooling of the unit requires extra power, which in turn requires a larger battery or constant power source, both not desired for the initial version of this remotely deployed unit. Secondly, on the exterior of the pyrgeometer, the sensor is covered with a clear silicon dome to protect the sensor from wind effects [18]. The prototype radiometer was fitted with a plastic cone around the sensor to help block the wind. Different sizes of cones were tested and the final design included a cone around the entire unit, rather than just the thermopile sensor.

As seen in Figure 4a, without wind protection and solar loading reduction, the temperature prediction varied by as much as $20 \mathrm{~K}$ from sample to sample. After the modifications for wind protection and temperature stabilization were included (Figure $4 \mathrm{~b}$ ), the temperature variation between samples reduced to approximately $5 \mathrm{~K}$.

Lab and field testing (as seen in Figure $4 \mathrm{~b}$ ) have also shown that it takes approximately $50 \mathrm{~min}$ for the electronics of the system to reach thermal equilibrium. The thermistor on the thermopile will not settle out until the electronics have reached thermal equilibrium.

\subsubsection{Validation of Temperature Prediction}

Once the radiometer was calibrated and characterized, its performance was compared to a commercially available FLIR infrared camera. The FLIR camera (model A6751sc SLS) is documented to be accurate within $2 \mathrm{~K}$ [22]. The blackbody was set to $303 \mathrm{~K}$ and both instruments recorded data for six minutes. The FLIR predicted the temperature as $303.54 \mathrm{~K}$ while the prototype radiometer predicted the temperature to be $302.50 \mathrm{~K}$. Comparing the prototype radiometer to the cooled FLIR camera validated 
that the prototype radiometer has accuracy in line with commercially available instruments, and the process to derive the coefficients in Equation (2) was sufficient for determining the target temperature.

\subsection{Target Emissivity}

To accurately predict the temperature of the surface using Equations (1) and (3), the emissivity of the target is required. The emissivity of the target material, which in this initial study was grass, was calculated using the Advanced Spaceborne Thermal Emission and Reflection Radiometer (ASTER) data from EOS-1 (Terra), specifically the ASTER global emissivity dataset (ASTER-GED). The ASTER-GED consists of emissivity maps at $100 \mathrm{~m}$ spatial resolution from data acquired between 2000 and 2008. The emissivity of the target was estimated by establishing an empirical relationship between the effective emissivity for each band of the prototype radiometer and ASTER Band 13 (10.25-10.95 $\mu \mathrm{m})$ and Band $14(10.95-11.65 \mu \mathrm{m})$ respectively using the natural material emissivity data provided by the ICESS group from the University of California Santa Barbara [23-25]. The emissivity of the geographic location of the deployed radiometer was then calculated from the empirical relationship and used in Equation (1).

\subsection{Atmospheric Study}

To calculate the sensor reaching radiance from Equation (1), the downwelled atmospheric radiance $\left(L_{d}\right)$ must be understood. Unlike the SURFRAD radiometers, the prototype radiometer does not record the downwelled irradiance. To determine the effect of downwelled radiance, an extensive atmospheric modeling study was conducted using the MODTRAN atmospheric radiance modeling tool by varying three independent variables, in turn creating 1020 atmospheric profiles. The first variable was the overall atmospheric profile using the MODTRAN pre-defined atmospheres of mid-latitude summer, mid-latitude winter, and tropical. The second variable altered the amount of column water vapor (CWV) over the target, varying from 0.0 to $3.2 \mathrm{~g} / \mathrm{cm}^{2}$ in $0.1 \mathrm{~g} / \mathrm{cm}^{2}$ steps. The final variable tested the effect of the sensor distance to target varying the altitude from 1.21 to $121 \mathrm{~m}$ by $12 \mathrm{~m}$ increments. The maximum altitude was selected based on Federal Aviation Administration (FAA) drone regulations, in the event that the radiometer was flown on a drone to increase ground spot size.

Since the surface temperature and emissivity are unknown for the target, a range of temperatures from $250 \mathrm{~K}$ to $320 \mathrm{~K}$ and an emissivity range from 0.905 to 0.984 were used to calculate the surface leaving radiance of the target. The temperature range was selected due to possible target temperatures in the field (spanning from snow-covered to desert targets), and the emissivity range was determined by the band effective emissivity using the 113 natural material emissivity curves provided by the ICESS group from the University of California Santa Barbara [23].

Placing the sensor at its intended height $(3 \mathrm{~m})$, the MODTRAN simulation confirmed that the upwelled radiance was near-zero $\left(L_{u}=0.001 \mathrm{~W} \mathrm{~m}^{-2} \mathrm{sr}^{-1} \mu \mathrm{m}^{-1}\right)$ and transmission values were approximately $1(\tau=0.999)$. Using the downwelled radiance values from MODTRAN, the sensor-reaching radiance was calculated via Equation 1, and the percentage of downwelled radiance in the total radiance was calculated to determine the overall effect.

Figure $5 \mathrm{a}, \mathrm{b}$ depict the downwelled radiance contribution as a percent of the total sensor-reaching radiance. From the initial MODTRAN run of 1020 atmospheric profiles, it was apparent that the pre-defined atmospheres (mid-latitude summer, mid-latitude winter, tropical) and height of the sensor had little impact on the overall percent of downwelled radiance (less than $1 \%$ ). Therefore, only the results for the mid-latitude summer atmosphere (most closely represented the RIT field collect site) and a sensor height of $3 \mathrm{~m}$ are displayed in the figures. The column water vapor was found to be the largest influence on the downwelled radiance contribution. The percent of downwelling radiance is shown as a function of column water vapor and as a function of target emissivity and temperature. The downwelled radiance results from the maximum (bottom curve) and minimum (top curve) target emissivities bound the range of possible emissivity values. However, from Section 2.3 the expected 
emissivity values for the target field for this study are 0.970 for Channel A and 0.962 for Channel B (closer to the maximum emissivity curve).

a)

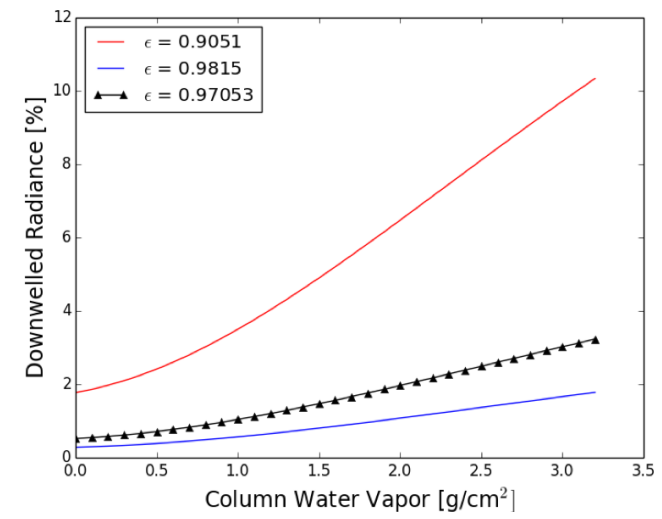

b)

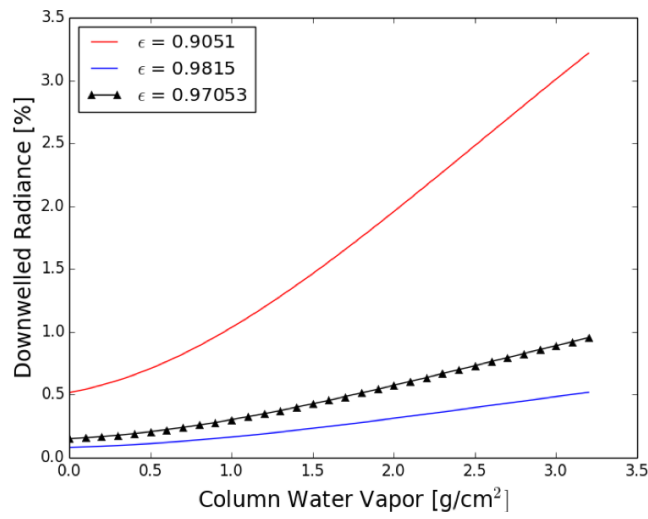

Figure 5. Downwelled radiance percentage of total radiance as a function of column water vapor with a target temperature of (a) $250 \mathrm{~K}$ and (b) $320 \mathrm{~K}$. The results are shown for a low emissivity target (top curve), a high emissivity target (bottom curve), and the intended target of $\varepsilon=0.970$ (middle curve).

To estimate the error in surface temperature prediction by not accounting for downwelling radiance, the surface temperature in Equation (1) was first calculated from the total sensor reaching radiance, then re-calculated by removing the downwelled contribution. When removing the highest percentage of downwelled radiance (lowest target temperature, highest CWV amount, and minimum emissivity value), the predicted temperature difference was $3.16 \mathrm{~K}$. As mentioned, the intended target for this initial study is a grass field $(\varepsilon=0.970)$. Therefore, when downwelled radiance is not accounted for, the predicted surface temperature error is $1.59 \mathrm{~K}$.

Based on the MODTRAN study, the error associated with the ST prediction from the prototype radiometers, even without accounting for the downwelled radiance, are small enough to be a significant improvement over the SURFRAD sites. This omission of the downwelled radiance component removes the need for a dedicated downwelled sensor or for characterizing the atmosphere between the target and the sensor, but this effect will be re-visited for future versions of the radiometer.

\subsection{Field-Based Experiments}

Once the prototype radiometer was characterized in the lab, field experiments were conducted concurrently with Landsat 8 overpasses. An open grass field at the southern end of the RIT campus in Rochester, NY was selected due to its similarity to the SURFRAD site in Goodwin Creek, MS. The field is assumed to be approximately uniform over a $400-\mathrm{m}$ area.

Due to orbital dynamics, Landsat 8 will pass over the same point on the Earth every 16 days. However, the RIT site is located in an overlap region of two adjacent Landsat paths (Path 17/Row 30 and Path 16/Row 30) enabling twice the measurements within the 16 day period (See Figure 6). Before each Landsat pass, the instrument is placed in the field looking nadir at the surface of the Earth. The instrument is mounted on a crossbar between two tripods to ensure that the field of view is not obstructed and that no shadows are cast onto the target area. The height of the instrument can vary, but preliminary testing showed no significant difference in temperature prediction by differing the height range from $0.3 \mathrm{~m}$ to $3 \mathrm{~m}$. The current setup has a height of $3 \mathrm{~m}$ and a second portable field unit is also available with a height of $1 \mathrm{~m}$. Figure 6 shows the setup of the RIT test rig and the portable test rig, with a radiometer attached. 


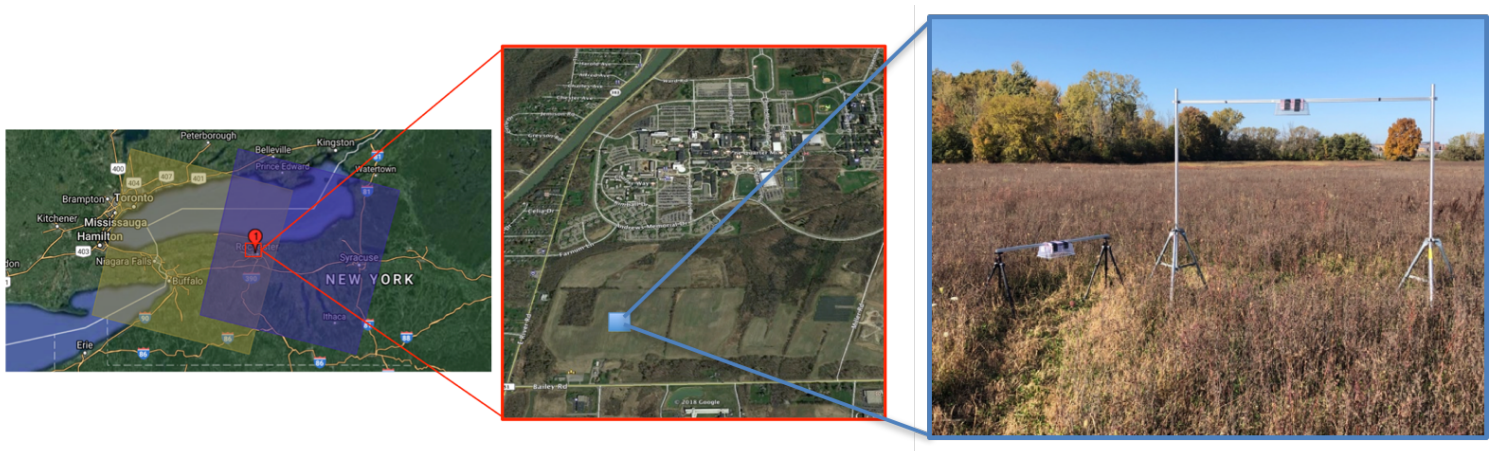

Figure 6. The target for the preliminary radiometer measurements is a grassy field located on the RIT campus in Rochester, NY. It is located in an overlap of two Landsat passes, allowing for twice the collects during a 16 day period.

The surface temperature is calculated using Equation (3) with the calculated emissivity, derived $\mathrm{n}, \mathrm{F}$, and F1 coefficients, and the output voltages from the thermopile (the output voltages are timestamped to easily match up the Landsat overpass). For the initial study of the prototype radiometer, the final target temperature is taken as an average of the measured temperatures from the two bands.

\section{Results and Discussion}

To date, 21 measurements concurrent with Landsat 8 overpasses have been collected with the prototype unit. Figure 7 shows the radiometer-measured vs. Landsat-derived surface temperature displayed by triangles. The average difference between the measured temperature and Landsat 8-derived ST is $1.37 \mathrm{~K}$ with a standard deviation of $1.34 \mathrm{~K}$. For reference, the SURFRAD-measured temperatures at the Goodwin Creek, MS site (data overlaid in Figure 7 as blue dots) had an average difference of $3.52 \mathrm{~K}$ with a standard deviation of $2.16 \mathrm{~K}$ as compared to the Landsat-derived ST. Goodwin Creek was chosen as the comparison site as its grass field is very similar to the RIT measurement location. Note that both data sets include a variety of cloud conditions with the pixel of interest (target) never being obstructed by clouds.

Two outlying points from the prototype radiometer are highlighted in Figure 7 with an " $x$ ". Both points resulted in a temperature prediction error over $4 \mathrm{~K}$ when compared to the Landsat 8-derived ST. On these collects, the winds were particularly high, confirming that wind will affect the accuracy of the radiometer. The high magnitude of error from the high wind suggest the need for a more advanced wind protection solution on future radiometers. The two outlier points are included in the overall average difference between measured and predicted temperature. If the outliers are not included, the average difference between measured temperature and Landsat 8-derived ST for the prototype radiometer is $0.99 \mathrm{~K}$ with a standard deviation of $0.87 \mathrm{~K}$.

The point at a Landsat 8-derived surface temperature of $322.7 \mathrm{~K}$, shown as a solid triangle, was collected by the radiometer in the Mojave desert California rather than the RIT site. The sand and sparse vegetation of the Mojave desert landscape is much different than the field at RIT (grass) so new emissivity coefficients were derived using the ASTER-GED database (Section 2.3). Testing against a different target than the RIT field and getting a temperature error of $1.49 \mathrm{~K}$, displayed the feasibility of using the radiometer in multiple environments over different types of surface targets. The surface temperature of the Mojave site $\left(50^{\circ} \mathrm{C}\right)$ was outside the range of the radiometer lab calibration $\left(0-45^{\circ} \mathrm{C}\right)$, demonstrating that the radiometer can be accurate over a larger temperature range. 


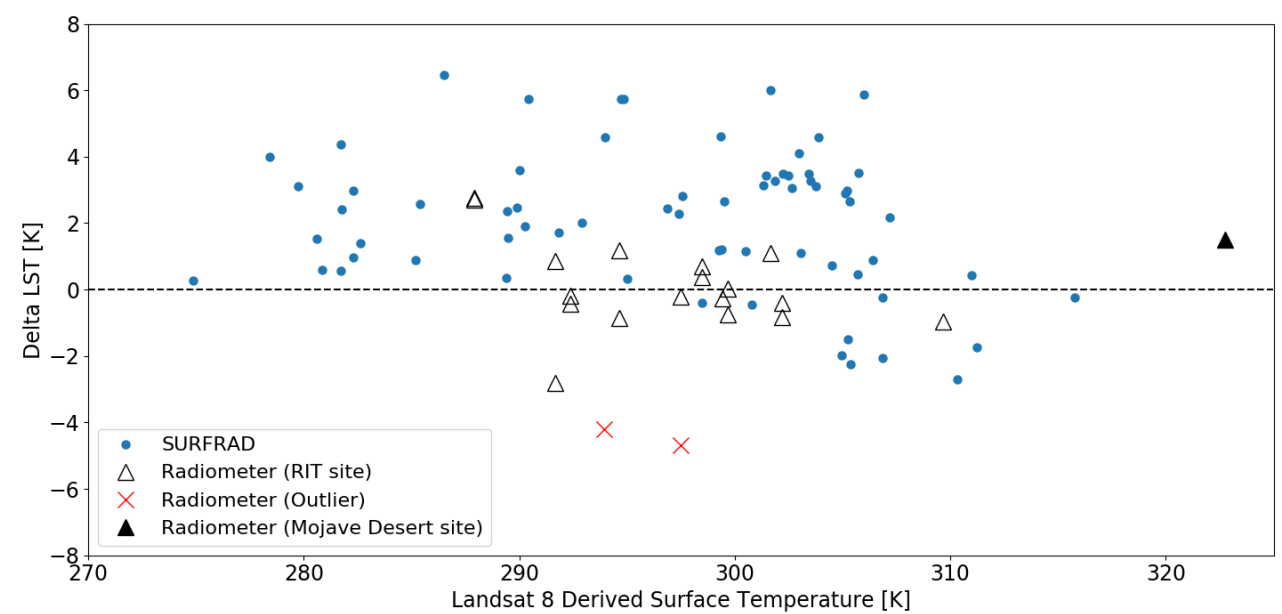

Figure 7. Difference between radiometer-measured and Landsat-derived surface temperatures for preliminary field collects that were conducted in the summer of 2019, along with the difference between SURFRAD-measured and Landsat-derived surface temperatures for reference.

The radiometer measurements can be used to adjust the calibration of the Landsat 8 TIRS bands. Figure 8 shows the radiometer-measured temperature versus the Landsat 8 -derived surface temperature with a 1:1 line drawn for reference. Another aspect of the radiometer data from Figure 8 is the wide temperature range $(273 \mathrm{~K}$ to $323 \mathrm{~K}$ ) of the ground targets. The low cost of the prototype radiometer allows for units to be fielded in multiple climate zones around the United States, which requires that the radiometer accurately predict the ST over a large range of temperature values. As the prototype radiometer's predictions are closely related to the one-to-one line, there is confidence in the radiometer's ability to perform over a wider temperature range than initially tested. The error bars shown in Figure 8 were calculated using the maximum error in temperature prediction due to the uncertainty of the target emissivity. The target emissivity range of 0.936 to 0.981 was found by calculating the band effective emissivity over 67 natural materials as referenced in Section 2.4, and an emissivity error of 0.05 corresponding to a temperature prediction error of $1.05 \mathrm{~K}$.

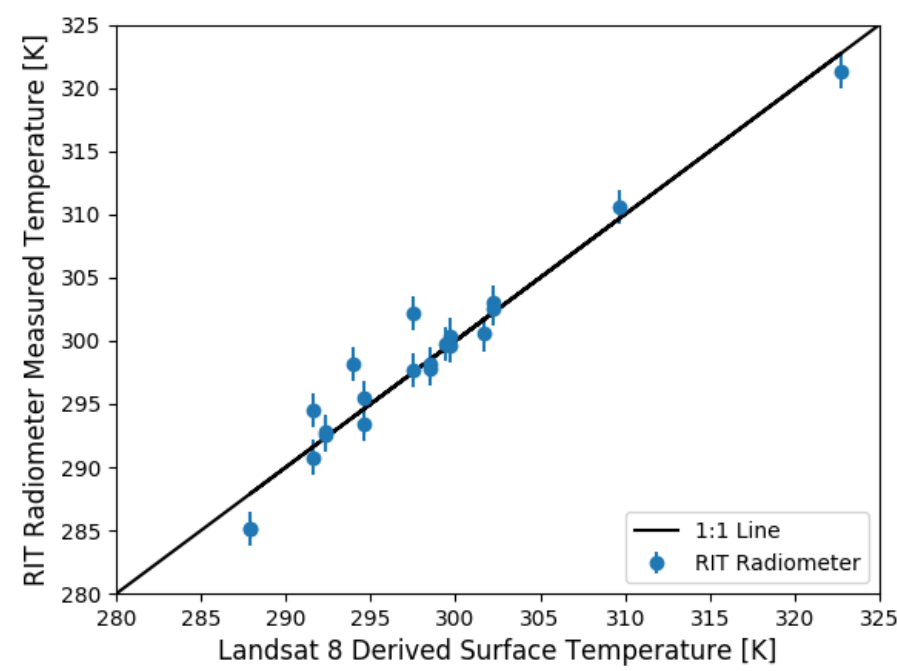

Figure 8. Radiometer-measured vs. Landsat-derived surface temperatures for preliminary field collects. The solid line compares the data to a 1:1 line, a metric similar to the one used by the Landsat calibration validation team [26]. 
This initial data set demonstrates that the prototype radiometer is statistically outperforming the pyrgeometers at the Goodwin Creek SURFRAD site as compared to Landsat 8-derived ST (lower average difference and smaller standard deviation as shown in Section 3). The studies referenced in Section 1 , in conjunction with these results, indicate that incorporating narrow-band spectral windows enable better estimates of emissivity, which reduces variation in surface temperature measurements. Future iterations of these radiometers, however, can incorporate three improvements to reduce overall temperature prediction errors. The characterization of emissivity using various thermal band combinations has been rigorously studied within the scientific community $[3,27,28]$. An accurate emissivity measurement, using the Temperature Emissivity Separation (TES) algorithm, is defined to be within 0.015 using a minimum of three to four spectral bands [28]. To eliminate the reliance on ASTER data and calculate the emissivity of the target with the radiometer, the next radiometer unit is designed to incorporate four additional response bands in the 8 to $9 \mu \mathrm{m}$ range. A four-channel thermopile was constructed by Dexter Laboratories [19] and will be integrated with the existing two band thermopile creating a six band radiometer. Using the calculated emissivity from the six-band radiometer, an updated MODTRAN simulation would produce a better estimate of the downwelled radiance. Applying this modeled downwelled radiance value to Equation (1), rather than using a value of zero, could result in lower overall temperature prediction error. Lastly, based on the two outliers from the field-collected data, further research of lowering wind interference across the sensor is required. The current wind protection device offers marginal improvement, whereas a sealed design similar to SURFRAD with high thermal transmittance should be investigated.

\section{Conclusions}

The number of scientific fields incorporating the application of ST products continues to increase. With this increase of users, Landsat and other Earth-observing platforms are pushed to deliver a more accurate ST product. The current ground-based network used to validate ST products (SURFRAD) collects measurements over a broad spectrum and is accurate to within $4 \mathrm{~K}$ of Landsat 8-derived ST [29]. The need for a ground network that is more accurate than the $2 \mathrm{~K}$ accuracy of the Landsat split-window ST algorithm [24] is apparent and was the focus of this study.

In this paper, the possibility of using low-cost, portable field radiometers to verify the Landsat 8-derived ST product was explored. This was accomplished by fabricating a prototype radiometer using a suite of low power electronics and a thermopile with narrow spectral bands that are similar to the TIRS sensor bands on Landsat 8. Lab characterizations resulted in the radiometer's ability to predict the temperature within $1.28 \mathrm{~K}$ of a known temperature source, with an NE $\Delta \mathrm{T}$ of $0.20 \mathrm{~K}$. Preliminary field testing with concurrent Landsat 8 overpasses produced temperature results within $1.37 \mathrm{~K}$ of the Landsat 8 -derived ST product. The prototype radiometer's ability to accurately predict the target temperature, along with the low cost of production, makes it a strong candidate for building a ground-based validation network over a range of surface types and emissivities.

Continued testing of the prototype radiometer is necessary for determining the temperature prediction accuracy in different climate zones and target materials (e.g., sand, rocks, mixed vegetation). To date, the prototype radiometer has predicted the temperature of high emissivity targets. Future planned field campaigns will test the prototype radiometer against low emissivity targets, such as sand, to determine the accuracy of the temperature predictions over a range of emissivity values. This data is crucial for determining where to build a network of radiometers to validate the Landsat-8 ST product.

A future effort includes testing the ability of the six band prototype radiometer to predict the accurate surface temperature and emissivity measurements. Windowing the spectral response coupled with a more accurate emissivity measurement shows promise that the prototype radiometer has the ability to validate Landsat 8-derived ST products lower than the stringent $1 \mathrm{~K}$ requirement [15]. If successful, a network of six band radiometers could measure the temperature and emissivity of a ground-based target, ensuring that users receive a more accurate worldwide Landsat ST product. 
Author Contributions: J.M. was responsible for initial conceptualization, data curation, methodologies \& validation efforts, and draft preparation. A.G. was responsible for funding acquisition, project administration, supervision, technical \& research support, and editing of this article. M.M. and R.E. provided technical \& research support and editing of this article. R.K. provided technical \& research support for the design and fabrication of the electronics. J.W. was responsible for the final design and fabrication of the electronic components. All authors have read and agreed to the published version of the manuscript.

Funding: The project presented in this publication was partially funded by NASA under Grant Number 80NSSC18K1529 and partially supported by Cooperative Agreement Number G19A00176 from the United States Geological Survey (USGS). The contents are solely the responsibility of the authors and do not necessarily represent the opinions or policies of NASA or the USGS. Mention of trade names or commercial products does not constitute their endorsement by NASA or the USGS. Note that this manuscript is submitted for publication with the understanding that the United States Government is authorized to reproduce and distribute reprints for Governmental purposes.

Acknowledgments: The authors would like to acknowledge Tania Kleynhans and Ben Kleynhans from the Rochester Institute of Technology. Tania Kleynhans provided invaluable insight in deriving the emissivity value of a surface target from ASTER data. Ben Kleynhans provided the software to easily calculate Landsat 8 ST for the radiometer-measured vs. Landsat-derived surface temperature comparison.

Conflicts of Interest: The authors declare no conflict of interest. The funders had no role in the design of the study; in the collection, analyses, or interpretation of data; in the writing of the manuscript, or in the decision to publish the results.

\section{References}

1. Hall, D.K.; Comiso, J.C.; Digirolamo, N.E.; Shuman, C.A.; Key, J.R.; Koenig, L.S. A satellite-derived climate-quality data record of the clear-sky surface temperature of the greenland ice sheet. J. Clim. 2012, 25, 4785-4798. [CrossRef]

2. Schneider, P.; Hook, S.J. Space observations of inland water bodies show rapid surface warming since 1985. Geophys. Res. Lett. 2010, 37, 1-5. [CrossRef]

3. Hulley, G.C.; Hook, S.J. Generating consistent land surface temperature and emissivity products between ASTER and MODIS data for earth science research. IEEE Geosci. Remote Sens. 2010, 49, 1304-1315. [CrossRef]

4. Rojas, O.; Vrieling, A.; Rembold, F. Assessing drought probability for agricultural areas in Africa with coarse resolution remote sensing imagery. Remote Sens. Environ. 2011, 115, 343-352. [CrossRef]

5. Anderson, M.C.; Hain, C.; Wardlow, B.; Pimstein, A.; Mecikalski, J.R.; Kustas, W.P. Evaluation of drought indices based on thermal remote sensing of evapotranspiration over the continental United States. J. Clim. 2011, 24, 2025-2044. [CrossRef]

6. Anderson, M.C.; Zolin, C.A.; Sentelhas, P.C.; Hain, C.R.; Semmens, K.; Yilmaz, M.T.; Gao, F.; Otkin, J.A.; Tetrault, R. The Evaporative Stress Index as an indicator of agricultural drought in Brazil: An assessment based on crop yield impacts. Remote Sens. Environ. 2016, 174, 82-99. [CrossRef]

7. Neteler, M.; Roiz, D.; Rocchini, D.; Castellani, C.; Rizzoli, A. Terra and Aqua satellites track tiger mosquito invasion: Modelling the potential distribution of Aedes albopictus in north-eastern Italy. Int. J. Health Geogr. 2011, 10. [CrossRef] [PubMed]

8. Anderson, M.C.; Allen, R.G.; Morse, A.; Kustas, W.P. Use of Landsat thermal imagery in monitoring evapotranspiration and managing water resources. Remote Sens. Environ. 2012, 122, 50-65. [CrossRef]

9. Anderson, M.C.; Kustas, W.P.; Norman, J.M.; Hain, C.R.; Mecikalski, J.R.; Schultz, L.; González-Dugo, M.P.; Cammalleri, C.; D'Urso, G.; Pimstein, A. Mapping daily evapotranspiration at field to continental scales using geostationary and polar orbiting satellite imagery. Hydrol. Earth Syst. Sci. 2011, 15, 223-239. [CrossRef]

10. Allen, R.G.; Tasumi, M.; Trezza, R. Satellite-based energy balance for mapping evapotranspiration with internalized calibration (METRIC)—Model. J. Irrig. Drain. Eng. 2007, 133, 380-394. [CrossRef]

11. Yu, Y.; Tarpley, D.; Privette, J.L.; Flynn, L.E.; Xu, H.; Chen, M.; Vinnikov, K.Y.; Sun, D.; Tian, Y. Validation of GOES-R satellite land surface temperature algorithm using SURFRAD ground measurements and statistical estimates of error properties. IEEE Geosci. Remote Sens. 2012, 50, 704-713. [CrossRef]

12. Heidinger, A.K.; Laszlo, I.; Molling, C.C.; Tarpley, D. Using SURFRAD to verify the NOAA single-channel land surface temperature algorithm. J. Atmos. Ocean. Technol. 2013, 30, 2868-2884. [CrossRef]

13. Li, S.; Yu, Y.; Sun, D.; Tarpley, D.; Zhan, X.; Chiu, L. Evaluation of 10 year AQUA/MODIS land surface temperature with SURFRAD observations. Int. J. Remote Sens. 2014, 35, 830-856. [CrossRef] 
14. Malakar, N.K.; Hulley, G.C.; Hook, S.J.; Laraby, K.; Cook, M.; Schott, J.R. An Operational Land Surface Temperature Product for Landsat Thermal Data: Methodology and Validation. IEEE Geosci. Remote Sens. 2018, 56, 5717-5735. [CrossRef]

15. Li, Z.L.; Tang, B.H.; Wu, H.; Ren, H.; Yan, G.; Wan, Z.; Trigo, I.F.; Sobrino, J.A. Satellite-derived land surface temperature: Current status and perspectives. Remote Sens. Environ. 2013, 131, 14-37. [CrossRef]

16. Wan, Z.; Zhang, Y.; Zhang, Q.; Li, Z.L. Validation of the land-surface temperature products retrieved from terra moderate resolution imaging spectroradiometer data. Remote Sens. Environ. 2002, 83, 163-180. [CrossRef]

17. Guillevic, P.; Göttsche, F.; Nickeson, J.; Hulley, G.; Ghent, D.; Yu, Y.; Trigo, I.; Hook, S.; Sobrino, J.A.; Remedios, J.; et al. Land Surface Temperature Product Validation Best Practice Protocol Version 1.1; Best Practice for Satellite-Derived Land Product Validation (p. 60); Land Product Validation Subgroup (WGCV/CEOS) Work Group on Calibration and Validation: Greenbelt, MD, USA, 2018.

18. Augustine, J.A.; DeLuisi, J.J.; Long, C.N. SURFRAD-A national surface radiation budget network for atmospheric research. Bull. Am. Meteorol. Soc. 2000, 81, 2341-2358. [CrossRef]

19. Introduction to Thermopile Detectors 2012; pp. 1-2. Available online: https://dexterresearch.com/technicallibrary/ (accessed on 1 December 2019).

20. SBIR Differential Blackbody. Available online: https://sbir.com/wp-content/uploads/2019/08/319-000294\{_\}G.pdf (accessed on 1 December 2019).

21. A Simple DC Radiometer; pp. 11-13. Available online: https://dexterresearch.com/technical-library/ (accessed on 1 December 2019).

22. FLIR Spec Sheet, 2004. Available online: https://www.flir.com/products/a6750-sls/ (accessed on 1 December 2019).

23. MODIS UCSB Emissivity Library. Available online: https://icess.eri.ucsb.edu/modis/EMIS/html/em.html (accessed on 1 December 2019).

24. Gerace, A.; Kleynhans, T.; Eon, R.; Montanaro, M. Towards an Operational Split Window-Derived Surface Temperature Product for the Thermal Infrared Sensors Onboard Landsat 8 \& 9. Remote Sens. 2020, 12, 224.

25. Hulley, G.C.; Hook, S.J.; Abbott, E.; Malakar, N.; Islam, T.; Abrams, M. The ASTER Global Emissivity Dataset (ASTER GED): Mapping Earth's emissivity at 100 meter spatial scale. Geophys. Res. Lett. 2015, 42, 7966-7976. [CrossRef]

26. Barsi, J.A.; Schott, J.R.; Hook, S.J.; Raqueno, N.G.; Markham, B.L.; Radocinski, R.G. Landsat-8 thermal infrared sensor (TIRS) vicarious radiometric calibration. Remote Sens. 2014, 6, 11607-11626. [CrossRef]

27. Malakar, N.K.; Hulley, G.C. A water vapor scaling model for improved land surface temperature and emissivity separation of MODIS thermal infrared data. Remote Sens. Environ. 2016, 182, 252-264. [CrossRef]

28. Gillespie, A.; Rokugawa, S.; Matsunaga, T.; Cothern, J.S.; Hook, S.; Kahle, A.B. A temperature and emissivity separation algorithm for Advanced Spaceborne Thermal Emission and Reflection Radiometer (ASTER) images. IEEE Geosci. Remote Sens. 1998, 36, 1113-1126. [CrossRef]

29. SURFRAD (Surface Radiation Budget) Network. Available online: https://www.esrl.noaa.gov/gmd/grad/ surfrad/overview.html (accessed on 1 December 2019).

(C) 2020 by the authors. Licensee MDPI, Basel, Switzerland. This article is an open access article distributed under the terms and conditions of the Creative Commons Attribution (CC BY) license (http://creativecommons.org/licenses/by/4.0/). 